\title{
Polychlorinated biphenyl residues in sandstorm depositions in Beijing, China
}

\author{
Shan Fu, Zhong-Zhi Yang, Ke Li, Xiao-Bai Xu* \\ State Key Laboratory of Environmental Chemistry and Ecotoxicology, Research Center for Eco-Environmental Sciences, Chinese Academy of Sciences, Post Office Box 2871, Beijing \\ 100085, People's Republic of China
}

\section{A R T I C L E I N F O}

\section{Article history:}

Received 27 January 2008

Received in revised form 11 April 2008

Accepted 19 June 2008

Available online 31 July 2008

\section{Keywords:}

China

Pollution

Polychlorinated biphenyls

Sandstorm deposition

\begin{abstract}
A B S T R A C T
Sandstorms, which distribute many particles, are a special atmospheric occurrence and are frequent in northern China. We conducted this study to determine, for the first time, the concentration of polychlorinated biphenyls (PCBs) in sandstorm depositions. We collected 13 samples from urban areas of Beijing, and we measured a total of 144 PCB congeners. Thirteen samples all contained PCB residues. The total PCB concentration ranged from 1.6 to $15.6 \mathrm{ngg}^{-1}$ (median, $4.8 \mathrm{ngg}^{-1}$, dry weight), with trichlorinated biphenyls as the predominant homologue (>50.4\%). Furthermore, we observed increasing PCB contamination from northwest to east Beijing. We later explored possible factors affecting contamination of the sandstorm depositions, which revealed a significant correlation between $\sum$ PCBs and the minimum particle size of the sandstorm deposition samples. Principal-component analysis revealed that the major source of PCBs in Beijing may be potentially associated with the number-one commercial PCB through the long-range transmission. In previous results, $\mathrm{PCBs}$ were not a severe component of contamination in sandstorm depositions of Beijing. However, this study suggested that sandstorm deposition may be a potential source of exposure to PCBs for the residents of Beijing, China.
\end{abstract}

(c) 2008 Elsevier Ltd. All rights reserved.

\section{Introduction}

Polychlorinated biphenyls (PCBs), listed along with 11 other compounds as persistent organic pollutants by the Stockholm Convention on May 22, 2001, are stable in the environment, can undergo long-range atmospheric transport, and can bioaccumulate through the food chain (UNECE, 1998; UNEP, 1998; The Secretariat of the Stockholm Convention and UNEP's Information Unit for Conventions, 2005). PCBs are a class of 209 congeners that were widely used in variety of electrical applications such as the dielectric fluid in transformers and large capacitors, heat-transfer fluids, and hydraulic fluids. Therefore, PCBs have been extensively studied with regard to their carcinogenic and mutagenic properties (IARC, 1987, 1997). Research results published so far have focused on central and western Europe, North America, and Japan. There is particularly a shortage of data from China and Russia (Meijer et al., 2003).

Long-range atmospheric transport and deposition of PCBs are important factors to consider for controlling the regional and global distribution of these pollutants and other persistent organic pollutants as well as for assessing their effect on ecosystems. Furthermore, sandstorms, which distribute many particles,

\footnotetext{
* Corresponding author. Tel.: +86 1062919177 ; fax: +86 1062923563 .

E-mail address: xuxb@rcees.ac.cn (X.-B. Xu).
}

are a special atmospheric occurrence and are frequent in northern China. For example, northern China experienced 11 sandstorms in 2006, one of which covered approximately one-eighth of China and deposited about 330000 tons of sand and dust in Beijing (Han et al., 2007; Lin and Chen, 2007). The regional characteristics of sand and dust sources are mainly arid or semiarid regions covered by deserts or land undergoing desertification in northern China (Wang et al., 2006). Wind-blown sand and floating dust not only remain in the areas where sandstorms occur but also extend to neighboring areas. The wind-blown sand extends either northeastward or southeastward, but floating dust extends mainly southeastward to low-latitude regions such as the East China Plain (Wang et al., 2003). Beijing, the capital of China, is one of the main cities affected by sandstorms and, with more than 12 million people, is one of the most densely populated cities in the world. The sources of human exposure to PCBs remain poorly understood. Natural and anthropogenic organic chemicals are transported within the atmosphere, while deposition events are important in helping to remove them (Scheringer et al., 2004). Because PCBs can easily accumulate in particles (Tasdemir et al., 2004), contamination of sandstorm deposition directly affects public health increasing the risk of human exposure by means of inhalation, ingestion or direct skin contact. We therefore need more information about the contamination status of PCBs in sandstorm depositions to better understand their environmental behavior and source-sink relationships. 
Because of the paucity of data on levels of PCBs in environmental media in China, we undertook this study to determine both the concentration and profile of PCBs in sandstorm deposition samples obtained from urban areas of Beijing. The main objectives of this study was to identify the possible sources of pollution in the sandstorm depositions of Beijing.

\section{Materials and methods}

\subsection{Samples}

A serious sandstorm developed from the Mongolian cyclone and blew over Beijing on April 16, 2006 (Han et al., 2007; Lin and Chen, 2007). The climate in Beijing then was dominated by temperate semiwet monsoon conditions, with a mean temperature of $14^{\circ} \mathrm{C}$ during the sampling period. We obtained sandstorm deposition samples from 13 urban sites in Beijing, China (Fig. 1) on April 17,2006 . The total sampling region area was $750 \mathrm{~km}^{2}$. We collected all samples from a platform $0.5-1.0 \mathrm{~m}$ in height and $3 \mathrm{~m}^{2}$ in area during daytime (between 8:00 a.m. and 6:00 p.m. [10 h day $\left.{ }^{-1}\right]$ ) with no precipitation. The collected samples were composites of three subsamples obtained at each sampling site. We then transferred the gathered samples to precleaned amber glass bottles and stored them at $4{ }^{\circ} \mathrm{C}$. Usually, we carried out extraction was within $72 \mathrm{~h}$. We collected and analyzed 13 samples for PCBs.

We analyzed the particle size distributions of the sandstorm deposition samples by using a Laser Particle Size Analyzer (Mastersizer 2000; Malvern Co., United Kingdom).

\subsection{Chemicals}

We purchased the standard solutions of PCB congeners from AccuStandard Inc. (New Haven, CT, USA). We diluted the five PCB calibration mixtures, which provided 144 congeners, with isooctane to $20 \mathrm{ng} \mathrm{ml}^{-1}$ for each congener. Table 1 shows the 144 PCB congeners. Decachlorobiphenyl (CB-209) as a surrogate was purchased from Supelco (Bellfonte, PA, USA). Standard reference material National Institute of Standards and Technology (NIST) 2585 (reference house dust for organic contaminant analysis) was obtained from NIST, GM, USA. All solvents used were of pesticide grade (J.T. Baker, Phillipsburg, NJ, USA).

\subsection{Extraction and cleanup}

We weight $5 \mathrm{~g}$ of each sandstorm deposition sample and then ground each one with anhydrous sodium sulfate into a free-flowing powder. We extracted the samples with $30 \mathrm{ml}$ of hexane/ dichloromethane $(1: 1, \mathrm{vol} / \mathrm{vol})$ by ultrasonication for $4 \mathrm{~min}$ and then centrifuged the samples at $3000 \mathrm{~g}$. We repeated this process three times. Before extraction, we added $10 \mathrm{ng}$ of CB-209 as a surrogate standard. We evaporated the concentrated extracts to $1 \mathrm{ml}$ in the Kuderna-Danish concentrator under a gentle $\mathrm{N}_{2}$ stream for cleanup.

We cleaned the concentrated extracts by using a chromatography column $(20 \mathrm{~cm} \times 15 \mathrm{~mm}$, internal diameter $)$ containing the following: $2 \mathrm{~g}$ of silver nitrate silica (10\%, wt/wt), $1 \mathrm{~g}$ of activated silica gel, $3 \mathrm{~g}$ of basic silica gel, $1 \mathrm{~g}$ of activated silica gel, $4 \mathrm{~g}$ of acid silica gel ( $44 \%$ concentrated sulfuric acid, wt/wt), $4 \mathrm{~g}$ of acid silica gel ( $22 \%$ concentrated sulfuric acid, wt/wt), $1 \mathrm{~g}$ of activated silica gel and $2 \mathrm{~g}$ of anhydrous sodium sulfate. We eluted the PCBs fraction with $100 \mathrm{ml}$ of hexane. We then evaporated the elution with a rotary evaporator and then reduced it to $50 \mu \mathrm{l}$ under a gentle $\mathrm{N}_{2}$ stream for analysis.

\subsection{Analysis}

We analyzed PCBs with an Agilent 6890 series gas chromatograph (GC) coupled with an Agilent 5973 mass spectrometer (MS) using electron impact ionization source in SIM mode. In electron impact ionization mode, the MS source temperature was $230^{\circ} \mathrm{C}$, and the electron energy was $70 \mathrm{eV}$. The $\mathrm{GC}$ was equipped with a split-splitless injector held constant at $270^{\circ} \mathrm{C}$. Gas chromatographic separation was performed on a $30-\mathrm{m}$ DB-5MS capillary column $(30 \mathrm{~m} \times 0.25 \mathrm{~mm}$, internal diameter; $0.25-\mu \mathrm{m}$ film thickness). We maintained the GC column at $75^{\circ} \mathrm{C}$ for $2 \mathrm{~min}$ and then ramped at $15^{\circ} \mathrm{C} / \mathrm{min}$ to $150^{\circ} \mathrm{C}$, further ramped at $2.5^{\circ} \mathrm{C} / \mathrm{min}$ to $280^{\circ} \mathrm{C}$, and held at this temperature for $15 \mathrm{~min}$. The total run time was $64 \mathrm{~min}$.

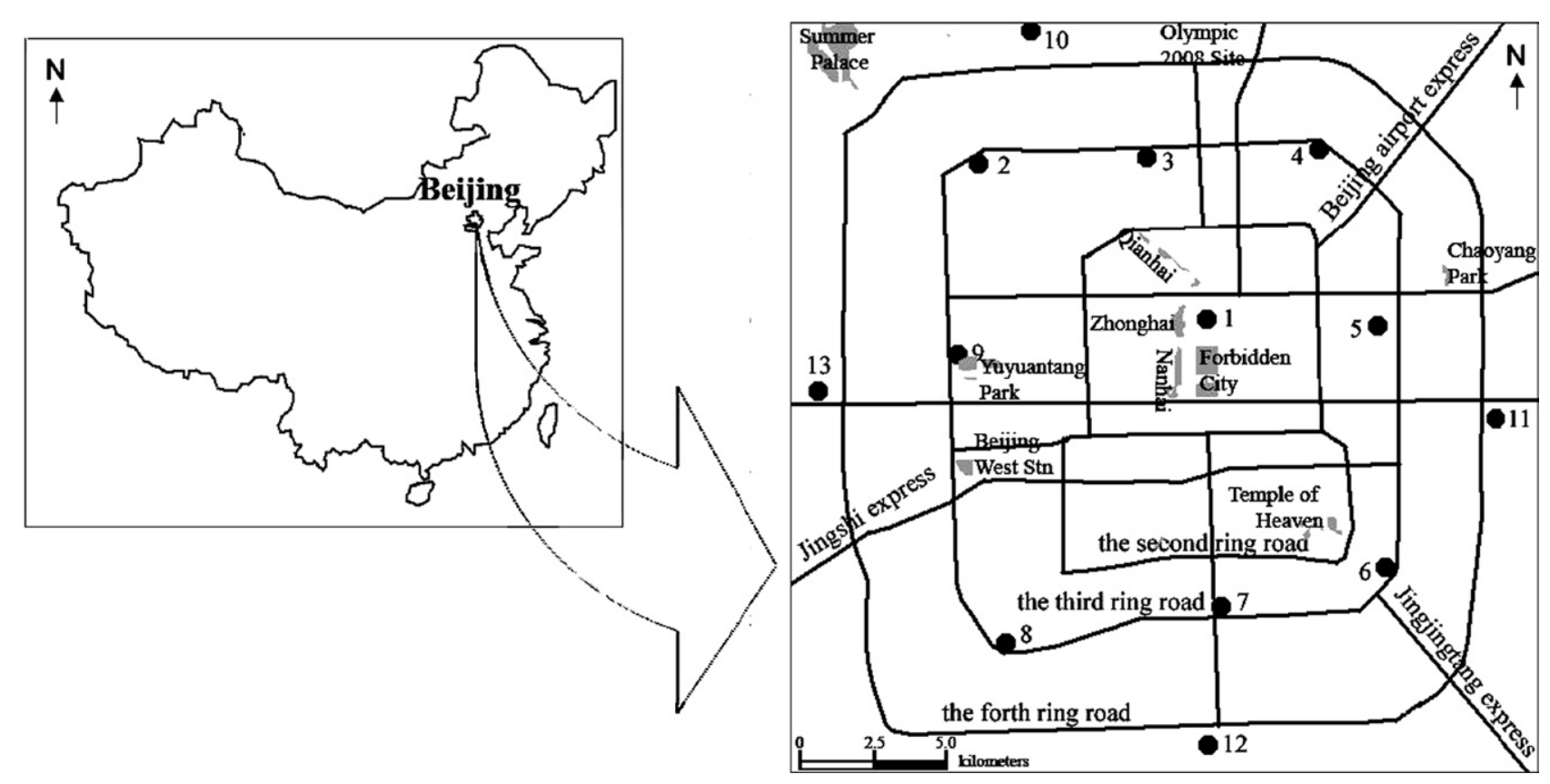

Fig. 1. Sampling sites of sandstorm deposition in urban areas of Beijing. 
Table 1

Selected 144 PCB congeners

\begin{tabular}{ll}
\hline PCB homologue & IUPAC number \\
\hline Mono-CBs & $1,2,3$ \\
Di-CBs & $4 / 10,9 / 7,6,8 / 5,14,12,13,15$ \\
Tri-CBs & $19,30,18,17,24 / 27,16 / 32,34,29,26,25,31,28,21,33 / 20,22$ \\
Tetra-CBs & $54,53,51,45,46,69,52 / 73,49,47 / 75 / 48,44,59 / 42$, \\
& $71 / 41 / 64,40,67,63,74,70,66,56 / 60,81,77$ \\
Penta-CBs & $104,103,100,93,95,91,92,84,90 / 101,99,119,83,97$, \\
& $117 / 87 / 115,85,110,82,124,107 / 109,123,118,114,122,105$ \\
Hexa-CBs & $136,154,151,135 / 144,147,149,134,165,146,153,132,141$, \\
& $137,130,164 / 163 / 138,158,129,128,167,156,157$ \\
Hepta-CBs & $179,176,178,175,187,183,185,174,177,171,173,172,180$, \\
& $193,191,170,190,189$ \\
Octa-CBs & $202,201,197,200,199,203 / 196,195,194,205$ \\
Nona-CBs & $208,207,206$ \\
Dec-CB & 209
\end{tabular}

\subsection{Quality control}

We ran a laboratory method control group to demonstrate the lack of interference and cross-contamination. We also ran a procedural blank in parallel with every set of six samples to further check for interference and cross-contamination. We analyzed duplicate samples in the laboratory along with the regular samples, for additional quality-control assessment to ensure valid results. We determined instrument stability and relative response factor variance by analyzing the calibration standard solutions in each sample batch.

We quantified PCBs by using an external standard method. We used three quality-control criteria to ensure correct identification of the target compounds: (1) GC retention times matched those of the standard compounds within $0.05 \mathrm{~min}$; (2) the signal-to-noise ratio was greater than $3: 1$; (3) each compound had two monitored ions. Isotopic ratios between quantitative and confirmation ions were within $15 \%$ of theoretical values. The limits of detection for PCBs were defined by a signal-to-noise ratio greater than three times the average baseline variation and were within the range of $0.01-0.05 \mathrm{ng} \mathrm{g}^{-1}$ (dry weight). The matrix spike recoveries of the 144 PCB congeners were within the range of $70-110 \%$, with a standard deviation of $10 \%$. The recovery of CB-209 surrogate in all samples was within the range of $75-115 \%$. The results met the acceptance criteria specified in the United States Environmental Protection Agency method 1668A (i.e., 25-150\%) (Environmental Protection Agency, 1999).

We analyzed the standard reference material sample (NIST2585 ) to validate the analytical method used. The results were satisfactory, with a $z$ score $\leqslant 1$ for all congeners (range, $0.06-0.84$ for the PCBs; $p<0.05$ ). Recovery of CB-209 surrogate was $85 \%$ with the
NIST 2585 sample, which also met the acceptance criteria specified in the US-EPA method 1668A.

\subsection{Data analysis}

The spatial distribution of PCBs was determined by Surfer 8.01 (Golden Software, Golden, CO, USA).

We carried out statistical analysis by using SPSS 13.0 for Windows (SPSS, Chicago, IL, USA). We used principal-component analysis (PCA), a multivariate statistical technique, to derive new components (principal components [PCs]) as a linear combination of the original variables, while PCs attempt to preserve the statistical relationships present in the original data. For this study, we investigated interspecies variations in the PCB congeners by using PCA. Initial variables considered were the concentration values of the PCB homologues. We normalized values of PCBs to a percentage of the sum of all congeners. To facilitate interpretation of results, we used rotation in the PCA with the varimax method.

\section{Results and discussion}

\subsection{PCB composition}

We identified PCBs in 13 sandstorm deposition samples. The total PCB concentrations (defined as the sum of 144 congeners) ranged from 1.6 to $15.6 \mathrm{ngg}^{-1}$ (median $4.8 \mathrm{ngg}^{-1}$, dry weight) (Table 2). There are few previous studies on sandstorm deposition. Furthermore, sandstorm deposition directly influences surface soil. Therefore, we compared the soil concentrations of PCBs reported elsewhere in the literature. The following areas were all affected by various degrees of sandstorm activity (Wang et al., 2003; Qiu et al., 2006). The median concentration in our study was similar to that of the soil of Beijing (3.1 $\mathrm{ng} \mathrm{g}^{-1}$ ) (Liu et al., 2006). In comparison with other areas surrounding Beijing, the levels were similar to those in agricultural surface soils of Shenyang $\left(6.4-15.0 \mathrm{ng} \mathrm{g}^{-1}\right)$ (Jing et al., 1992), surface soils of Qingdao (3.1-15.0 ng g $^{-1}$ ) (Geng et al., 2006) and agricultural soils of Southern Jiangsu province (4.13 $\mathrm{ng} \mathrm{g}^{-1}$ ) (Zhang et al., 2007). This result indicated that the distribution of PCBs in sandstorm depositions in Beijing and in soils in Beijing and the surrounding region is much more uniform, possibly because of long-range atmospheric transportation (Meng et al., 2000). Furthermore, sandstorms might play a specific role in the long-range transmission. Because so far no threshold values of PCBs have been defined for soils or sandstorm depositions in China, we used as a reference of contamination the target value of the Dutch List that was formulated to distinguish between clean and polluted soils in The Netherlands (VROM, 2000). Compared with the allowable level of $20 \mu \mathrm{g} \mathrm{kg}^{-1}$ for the total concentration of

Table 2

Total concentration of PCB homologues in each sample (data units are in nanograms per gram; ND, not detected)

\begin{tabular}{|c|c|c|c|c|c|c|c|c|c|c|}
\hline $\begin{array}{l}\text { Sample } \\
\text { No. }\end{array}$ & $\begin{array}{l}\text { Mono- } \\
\text { CBs }\end{array}$ & $\begin{array}{l}\text { Di- } \\
\text { CBs }\end{array}$ & $\begin{array}{l}\text { Tri- } \\
\text { CBs }\end{array}$ & $\begin{array}{l}\text { Tetra- } \\
\text { CBs }\end{array}$ & $\begin{array}{l}\text { Penta- } \\
\text { CBs }\end{array}$ & $\begin{array}{l}\text { Hexa- } \\
\text { CBs }\end{array}$ & $\begin{array}{l}\text { Hepta- } \\
\text { CBs }\end{array}$ & $\begin{array}{l}\text { Octa- } \\
\text { CBs }\end{array}$ & $\begin{array}{l}\text { Nona- } \\
\text { CBs }\end{array}$ & $\sum$ PCBs \\
\hline 1 & N.D. & 0.2 & 1.5 & 0.9 & 0.1 & 0.1 & 0.1 & 0.1 & N.D. & 2.9 \\
\hline 2 & N.D. & 0.4 & 4.5 & 0.5 & 0.2 & 0.2 & N.D. & N.D. & N.D. & 5.8 \\
\hline 3 & N.D. & 0.3 & 3.8 & 0.5 & 0.2 & 0.2 & N.D. & N.D. & N.D. & 5.1 \\
\hline 4 & N.D. & N.D. & 2.8 & 0.7 & 0.4 & 0.2 & N.D. & N.D. & N.D. & 4.1 \\
\hline 5 & N.D. & 1.4 & 10.7 & 2.5 & 0.6 & 0.3 & 0.1 & N.D. & N.D. & 15.6 \\
\hline 6 & N.D. & 0.5 & 6.4 & 1.1 & N.D. & 0.1 & 0.1 & N.D. & N.D. & 8.2 \\
\hline 7 & N.D. & 0.1 & 2.7 & 0.2 & N.D. & 0.2 & 0.1 & N.D. & N.D. & 3.4 \\
\hline 8 & N.D. & 0.1 & 1.1 & 0.3 & N.D. & 0.1 & N.D. & N.D. & N.D. & 1.6 \\
\hline 9 & N.D. & 0.1 & 2.5 & N.D. & 0.5 & 0.2 & 0.1 & N.D. & N.D. & 3.5 \\
\hline 10 & N.D. & N.D. & 9.1 & 1.6 & 0.4 & 0.3 & 0.1 & 0.1 & N.D. & 11.4 \\
\hline 11 & N.D. & N.D. & 4.5 & 0.2 & N.D. & 0.1 & N.D. & N.D. & N.D. & 4.8 \\
\hline 12 & N.D. & N.D. & 1.9 & 0.3 & 0.5 & 0.2 & N.D. & N.D. & N.D. & 2.9 \\
\hline 13 & N.D. & 0.5 & 8.7 & 1.7 & 0.6 & 0.5 & 0.1 & N.D. & N.D. & 12.1 \\
\hline
\end{tabular}


six PCB congeners approved by the Dutch List, the contamination of sandstorm depositions in our study had relatively slight PCB contamination levels on average.

\subsection{PCB profiles}

In China, approximately 10000 tons of PCBs were produced from 1965 to 1974, with 9000 tons as trichlorobiphenyl (the \#1 PCB) and 1000 tons as pentachlorobiphenyl (the \#2 PCB) (Xing et al., 2005). The \#1 PCB contained $42 \%$ chlorine, which was similar to Aroclor 1242, and the \#2 PCB contained 53\% chlorine, similar to Aroclor 1254 (Jiang et al., 1997). The major homologue produced and used in China was tri-CBs, the major homologue profile of the global PCB product was also tri-CBs, and the composition of tri-CBs was higher in Chinese products than in global products (40.4\% versus $25.2 \%$ for tri-CBs) (Breivik et al., 2002). Therefore, tri-CBs should be the dominant PCBs in the sandstorm depositions of Beijing.

Of the PCB homologues, the dominant PCBs detected in this study were indeed tri-CBs, accounting for more than $50.4 \%$ of the total PCBs in all sampling locations (Table 2). Higher-chlorinated homologues were detected at relatively low concentrations. The main PCB homologue in the average Chinese background and rural soils was also tri-CBs (55\% and 38\%, respectively) (Ren et al., 2007). The similarities of PCB patterns between sandstorm deposition and Chinese soil may indicate a common source origin.

\section{3. $P C A$}

We performed PCA to evaluate similarities or differences between the PCB homologue patterns of each sample; we normalized all data to percentage of $\sum$ PCBs. PCs were determined by an eigenvalue of more than 1 . By processing, two extracted PCs could explain $62.4 \%$ of the data variance. A loading plot and score plot rotation were obtained after varimax. Component 1 in Fig. 2 accounted for $36.5 \%$ of the total variance and was characterized by higher-chlorinated homologues, whereas component 2 accounted for $25.9 \%$ and was characterized by lower-chlorinated homologues. The score plot (Fig. 3) indicated that the compositions of PCBs in the sandstorm deposition samples were similar, possibly originating from the same source. The PCBs found in Beijing could therefore be classified into one main group that was relatively highly contaminated by tri-CBs. We also observed a clear clustering of samples, showing that tri-CBs are indeed the dominant contaminant in the sandstorm deposition of Beijing. All these samples as well as the \#1 commercial PCB were characterized by a higher proportion of tri-CBs in the PCB profiles, which indicates that the sources of PCBs for these sampling locations may be potentially associated with the \#1 commercial PCB through long-range transmission.

\section{4. $P C B$ distribution}

Fig. 4 shows the distribution of $\sum$ PCBs in the sandstorm deposition samples, with an increasing trend from northwest to east Beijing. It is interesting to explore a correlation between $\sum$ PCBs and the minimum particle sizes of the sandstorm deposition samples. We analyzed the particle size distributions of the sandstorm deposition samples by using a Laser Particle Size Analyser; the data are shown in Table 3. A statistically significant correlation existed between the $\sum$ PCBs and minimum particle sizes $(r=0.81$; Fig. 5). This finding indicated that the $\sum$ PCBs were associated with the particle size distribution and that they were removed through the scavenging of particulates. Another possible reason is the influence of the northwest wind during the study period. As a result, PCBs could be absorbed by smaller atmosphere particles

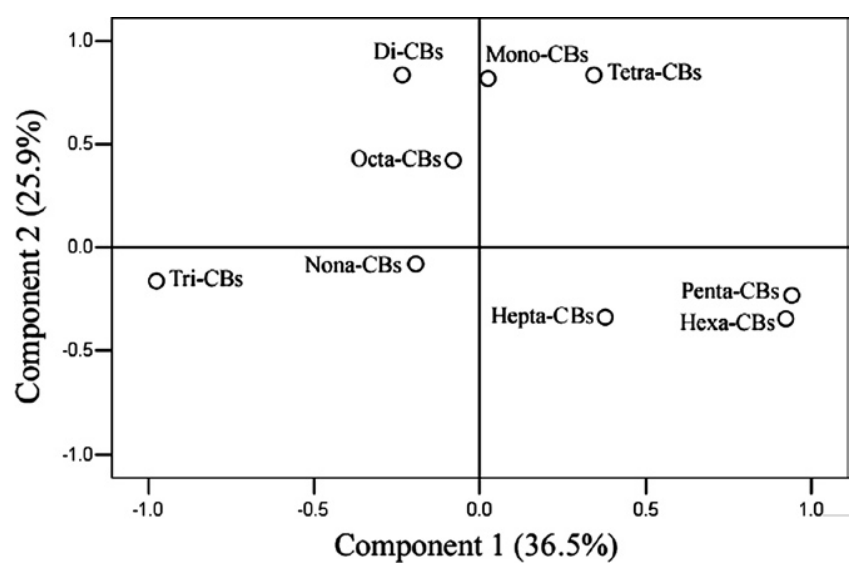

Fig. 2. Two-dimensional principal-component loading plot obtained from the data correlation matrix of 13 sandstorm deposition samples in Beijing.

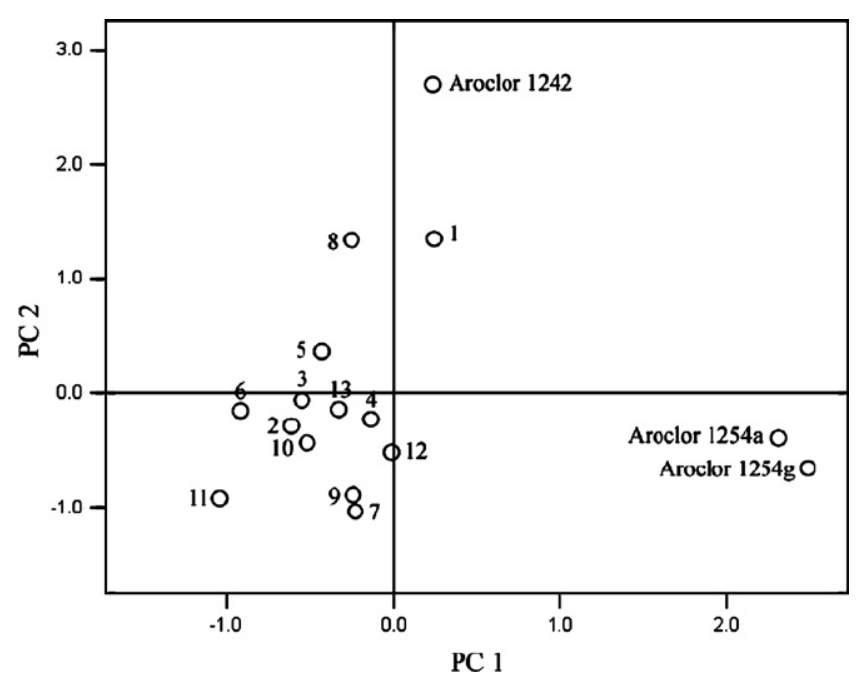

Fig. 3. Two-dimensional principal-component score plot obtained from the data correlation matrix of 13 sandstorm deposition samples in Beijing.

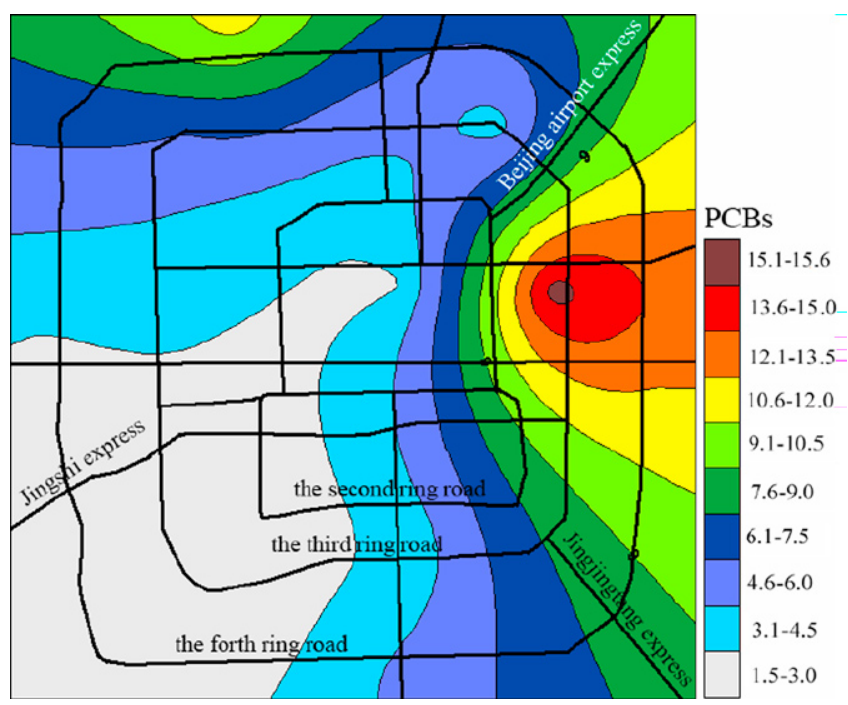

Fig. 4. Distribution of $\sum \mathrm{PCB}$ in urban areas of Beijing (data units in the figure are nanograms per gram). 
Table 3

Particle size distributions of sandstorm deposition samples

\begin{tabular}{llll}
\hline \multirow{2}{*}{$\begin{array}{l}\text { Nample } \\
\text { No. }\end{array}$} & \multicolumn{2}{l}{ Particle size $(\mu \mathrm{m})($ particle number\%) } \\
\cline { 2 - 4 } & $<\mathrm{d} 1(10 \%)$ & $<\mathrm{d} 2(50 \%)$ & $<\mathrm{d} 3(90 \%)$ \\
\hline 1 & 11.3 & 34.6 & 80.3 \\
2 & 11.2 & 33.3 & 73.1 \\
3 & 12.6 & 38.7 & 110.1 \\
4 & 10.6 & 39.0 & 104.9 \\
5 & 9.0 & 35.8 & 100.4 \\
6 & 10.2 & 31.7 & 69.5 \\
7 & 13.78 & 39.9 & 88.3 \\
8 & 12.0 & 37.5 & 83.8 \\
9 & 12.1 & 35.8 & 82.0 \\
10 & 9.2 & 32.7 & 85.4 \\
11 & 9.8 & 36.8 & 102.5 \\
12 & 11.7 & 40.6 & 114.6 \\
13 & 11.1 & 37.0 & 118.9 \\
\hline
\end{tabular}

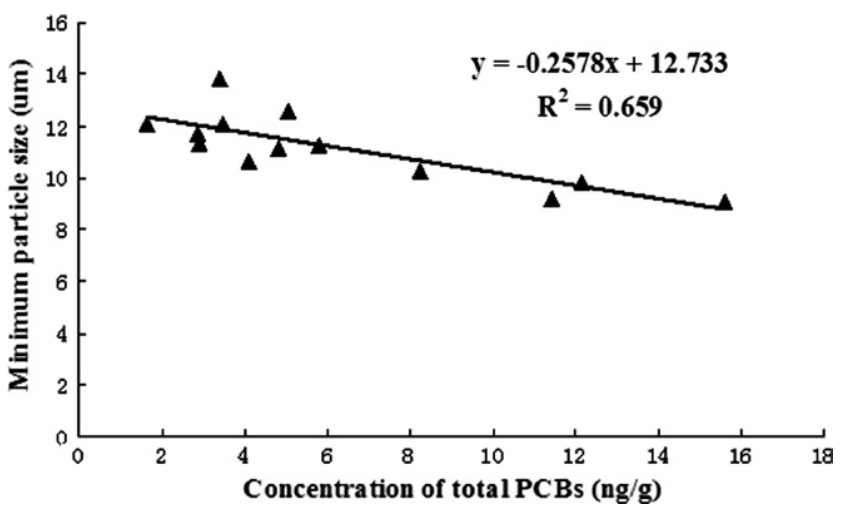

Fig. 5. Correlation between minimum particle sizes and total PCBs of Beijing sandstorm deposition samples.

that mixed with the passing deposition before being transported and deposited in eastern areas of Beijing, resulting in higher concentrations.

\section{Acknowledgment}

This study was supported by the National Natural Scientific Foundation of China (No. 20707031).

\section{References}

Breivik, K., Sweetman, A., Pacyna, J.M., Jones, K.C., 2002. Towards a global historical emission inventory for selected PCB congeners - a mass balance approach 1 . Global production and consumption. Sci. Total Environ. 290, 181-198.

Environmental Protection Agency, 1999. US EPA. Method 1668, Revision A: Chlorinated Biphenyl Congeners in Water, Soil, Sediment, and Tissue by HRGC/HRMS.
EPA-821-R-00-002. EPA, Washington, DC, US Available from: <http://www.epa. gov/Region3/1668a.pdf>.

Geng, C.Z., Li, M.L., Yang, Y.L., Zhang, L.F., Nie, L.M., 2006. Study and analysis of pollution levels of OCPs and PCBs in soil in Qingdao area. J. Qingdao Univ. Eng Technol. 21, 42-48, (in Chinese).

Han, T., Lin, J., Wang, Y., Zheng, B., Song, H., Liu, J., Jiang, G., Shi, P., Zhang, J., 2007. Nature and control of "dust storms" in the Beijing-Tianjin region, China - a case study of the dust storm in Beijing on April 16, 2006. Bull. Geod. 26, 117-127, (in Chinese).

IARC, 1987. Overall evaluations of carcinogenicity: an updating of IARC monographs. In: Monographs on the Evaluation of Carcinogenic Risks to Humans, vols. 1-42. International Agency for Research on Cancer, Lyon, (Suppl. 7).

IARC, 1997. Polychlorinated dibenzo-para-dioxins and polychlorinated dibenzofurans. Monographs on the Evaluation of Carcinogenic Risks to Humans. International Agency for Research on Cancer, Lyon. 69.

Jiang, K., Li, L., Chen, Y., Jin, J., 1997. Determination of PCDD/Fs and dioxin-like PCBs in Chinese commercial PCBs and emissions from a testing PCB incinerator. Chemosphere 34, 941-950.

Jing, Z.Y., Li, Y.H., Feng, X.B., Wang, F.Q., Zhang, Y.X., 1992. The study of polychlorinated biphenyls for their loss, contamination and protection strategy in Shengyang City. Cong Kan Environ. Sci. 13, 1-28, (in Chinese).

Lin, Y.W., Chen, Y.L., 2007. The Price of Global Warming. Glo. Bus. 6, 86-87, (in Chinese).

Liu, G., Chen, Z., Shi, Y., Wang, G., Li, W., Li, C., 2006. The levels and compositions of PCBs in Beijing soil. Acta Sci. Cirum. 26, 2013-2017, (in Chinese).

Meijer, S.N., Ockenden, W.A., Sweetman, A., Breivik, K., Grimalt, J.O., Jones, K.C., 2003. Global distribution and budget of PCBs and HCB in background surface soils: implications for sources and environmental processes. Environ. Sci. Technol. 37, 667-672.

Meng, Q.Y., Bi, X.H., Chu, S.G., Xu, X.B., 2000. Preliminary study of the characterization and distribution of PCB congeners between vapor phase and aerosols in polluted area. Environ. Chem. 19, 501-506, (in Chinese).

Qiu, Y.J., Zou, X.Y., Zhang, C.L., 2006. Research on impact of dust event frequency on atmosphere visibility variance: a case study of typical weather stations locating in the dust route to Beijing. Environ. Sci. 27, 1046-1051, (in Chinese).

Ren, N.Q., Que, M.X., Li, Y.F., Liu, Y., Wang, X.N., Xu, D.D., Sverko, E., Ma, J.M., 2007. Polychlorinated biphenyls in Chinese surface soils. Environ. Sci. Technol. 41, 3871-3876.

Scheringer, M., Salzmann, M., Stroebe, M., Wegmann, F., Fenner, K., Hungerbuhler, K., 2004. Long-range transport and global fractionation of POPs: insights from multimedia modeling studies. Environ. Pollut. 128, 177-188.

The Secretariat of the Stockholm Convention and UNEP's Information Unit for Conventions, 2005. Ridding the world of POPs: a guide to the Stockholm Convention on persistent organic pollutants. UNEP, Geneva, Switzerland Available from: <http://www.pops.int/documents/guidance/beg_guide.pdf>.

Tasdemir, Y., Odabasi, M., Vardar, N., Sofuoglu, A., Murphy, T.J., Holsen, T.M., 2004 Dry deposition fluxes and velocities of polychlorinated biphenyls (PCBs) associated with particles. Atmo. Environ. 38, 2447-2456.

UNECE, 1998. Protocol on Persistent Organic Pollutants Under the 1979 Convention on Long-Range Transboundary Air Pollution (ECE/EB.Air/60). United Nations Economic Commission for Europe: Geneva.

UNEP, 1998. Preparation of an Internationally Legally Binding Instrument for Implementing International Action on Certain Persistent Organic Pollutants; UNEP/ POPs/Inc.1/6. United Nations Environment Programme: Nairobi, Kenya.

VROM, 2000. Circular on Target Values and Intervention Values for Soil Remediation. DBO/07494913, VROM (The Housing, Spatial Planning and Environment).

Wang, S.G., Wang, J.Y., Zhou, Z.J., Shang, K.Z., Yang, D.B., Zhao, Z.S., 2003. Regional characteristics of dust events in China. Acta. Geo. Sin. 58, 193-200, (in Chinese).

Wang, J., He, T., Guo, X., Liu, A., Zhou, O., 2006. Dynamic changes of sandy land in northwest of Beijing, China. Environ. Monit. Assess. 121, 109-125.

Xing, Y., Lu, Y., Dawson, R.W., Shi, Y., Zhang, H., Wang, T., Liu, W., Ren, H., 2005. A spatial temporal assessment of pollution from PCBs in China. Chemosphere 60 731-739.

Zhang, J.Y., Qiu, L.M., He, J., Liao, Y., Luo, Y.M., 2007. Occurrence and congeners specific of polychlorinated biphenyls in agricultural soils from Southern Jiangsu, China. J. Environ. Sci. 19, 338-342. 